\title{
Urology resident training in laparoscopic surgery - results of the first national survey in Poland
}

\author{
Bartosz Brzoszczyk ${ }^{1}$, Tomasz Milecki ${ }^{2}$, Piotr Jarzemski ${ }^{1}$, Andrzej Antczak ${ }^{2}$, Artur Antoniewicz ${ }^{3}$, Anna Kołodziej ${ }^{4}$ \\ 1Department and Clinic of Urology, Jan Biziel University Hospital, Bydgoszcz, Poland \\ ${ }^{2}$ Department and Clinic of Urology and Oncological Urology, Poznan University of Medical Sciences, Poznan, Poland \\ ${ }^{3}$ Department of Urology, Multidisciplinary Hospital, Warsaw Miedzylesie, Poland \\ ${ }^{4}$ Department and Clinic of Urology, Wroclaw Medical University, Wroclaw, Poland
}

Videosurgery Miniinv 2019; 14 (3): 433-441

DOI: https://doi.org/10.5114/wiitm.2019.81439

\begin{abstract}
Introduction: For many urological procedures the open approach is being replaced by the laparoscopic approach. Laparoscopy technique requires special training conditions. A well-designed, step-by step training program is significantly important for shortening the learning curve.

Aim: The purpose of the study was to evaluate urology residents' (UR) experience in laparoscopic procedures, training patterns and facilities available in departments of urology in Poland.

Material and methods: The survey developed by the authors included 18 questions concerning laparoscopy training and was distributed among UR who participated in 2 courses in laparoscopic surgery for UR in Poland in 2017. The survey consisted of questions regarding the number of laparoscopic procedures, acquired laparoscopic experience, laparoscopic simulation training and motivation for further learning.

Results: Of the 2017 invited UR in Poland, 108 (34\%) completed the survey. Seventy-two (78\%) UR from the study group have access to laparoscopic surgery in their department. Only 20 (25\%) of urology departments are equipped with a laparoscopy box and a small number of UR perform regular training. As a primary operator basic (varicocele repair) and advanced (e.g. radical nephrectomy, radical prostatectomy, nephron-sparing surgery) laparoscopic procedures are performed respectively by $55(71 \%)$ UR and $8(10 \%)$ UR. Most residents evaluated their laparoscopic skills as poor (15, 19\%), very poor (31,40\%) or absent (10,13\%), while only $22(28 \%)$ evaluated them as at least satisfactory.

Conclusions: Laparoscopic technique is available in most Polish training centers. However, the majority of UR consider their skills unsatisfactory. Additionally, a large number of Polish UR do not have access to intensive training. UR considered that their availability of training courses and fellowships is low. Surgical exposure among Polish UR comprises mainly minor laparoscopic procedures.
\end{abstract}

Key words: laparoscopy, education, surgical training, urology, residency.

\section{Introduction}

Minimally invasive techniques, mainly including laparoscopic and robot-assisted techniques, are currently the primary tools used in the surgical treat- ment of urologic diseases [1]. Laparoscopic surgery has been widely accepted in general urological practice and has now become the standard. The first laparoscopic procedures in Poland were carried out only a few years after the first pioneer procedures

\footnotetext{
Address for correspondence

Tomasz Milecki, Department and Clinic of Urology and Oncological Urology, Poznan University of Medical Sciences, 3 Szwajcarska St, 61-285 Poznan, Poland, phone: +48 601313 673, e-mail: mileckito@gmail.com
} 
in Europe (laparoscopic radical nephrectomy at the Pomeranian Medical University in Szczecin - 1993 vs. 1990, laparoscopic radical prostatectomy at the Jan Biziel University Hospital in Bydgoszcz - 1995 vs. 1991) [2]. The laparoscopic technique has its limitations associated with the loss of three-dimensional vision, depth perception, increased costs compared to open surgery, and, above all, a long learning curve $[3,4]$. Special training conditions and skills are required; hence numerous training programs have been developed to facilitate teaching laparoscopy [5]. On the basis of European programs the Polish concept of "Uro-lap" was created, whose main assumptions were published in 2007 [6].

\section{Aim}

The aim of the study is to assess the implementation of the Uro-lap concept, quality of laparoscopic

Table I. Demographic data of UR with access to laparoscopic surgery in their department and laparoscopic department characterization $(n=78)$

\begin{tabular}{|c|c|}
\hline Parameter & Value \\
\hline \multicolumn{2}{|l|}{ Residency year: } \\
\hline 1 & $13(16.7 \%)$ \\
\hline 2 & $9(11.5 \%)$ \\
\hline 3 & $26(33.4 \%)$ \\
\hline 4 & $22(28.2 \%)$ \\
\hline 5 & $4(5.1 \%)$ \\
\hline 6 & $4(5.1 \%)$ \\
\hline \multicolumn{2}{|l|}{ Hospital type: } \\
\hline Clinical center & $36(46 \%)$ \\
\hline Other & $42(54 \%)$ \\
\hline $\begin{array}{l}\text { Number of laparoscopic surgeons } \\
\text { in the department }\end{array}$ & $\begin{array}{l}\text { Average: } 3.32 \pm 2.11 \\
\text { min. } 0, \max .12\end{array}$ \\
\hline $\begin{array}{l}\text { Number of residents in the depart- } \\
\text { ment }\end{array}$ & $\begin{array}{l}\text { Average: } 4.86 \pm 2.54 \text {, } \\
\text { min. } 1, \max .11\end{array}$ \\
\hline \multicolumn{2}{|l|}{$\begin{array}{l}\text { Number of laparoscopic procedures } \\
\text { per year in the department: }\end{array}$} \\
\hline$<50$ & $29(37.2 \%)$ \\
\hline $50-100$ & $21(26.9 \%)$ \\
\hline $100-150$ & $4(5.1 \%)$ \\
\hline$>200$ & $24(30.8 \%)$ \\
\hline
\end{tabular}

training, and possibilities for acquiring knowledge and skills in laparoscopic techniques among urology residents' (UR) in Poland.

\section{Material and methods}

For the purpose of the study we created an anonymous survey containing 17 questions concerning the quality of laparoscopic training in Poland. With the approval of the organizers of the $25^{\text {th }}$ Symposium of Endourology and SWL and the $47^{\text {th }}$ Congress of the Polish Urological Association, UR participating in both scientific meetings and undergoing residency in urology were invited to take part in the survey. The survey was based on questionnaires for analyzing the status of laparoscopic training in the rest of Europe, USA and Canada in order to compare the results obtained in Poland (Appendix 1) [3, 7-9].

It consisted mainly of multiple choice questions concerning the demographic data of the respondents, laparoscopic training opportunities, experience in performing laparoscopic procedures, number of procedures, subjective evaluation of own skills, and expected skill level at the end of residency.

\section{Statistical analysis}

The collected data were subjected to statistical analysis using Statistica 13.0 software.

\section{Results}

The study included 108 participants from centers providing training in urology. Individuals who have access to laparoscopic education in their centers constituted $72 \%(n=78)$ of the entire group. Data obtained from UR, who at the time of survey had not been undergoing laparoscopic training in their home centers, were analyzed separately. The main analysis included questionnaires filled in by 78 UR with access to laparoscopic education in their department.

Table I presents the demographic data of survey participants. Almost half of the respondents (46\%) undergo training in a clinical center. The number of laparoscopic surgeons in training centers varies (min. $=0$, $\max .=12$ operating surgeons); on average 3.3 experienced urologists operate using laparoscopic techniques. Similarly, the number of UR varies depending on the center $(\min .=1, \max .=11$ residents). More than half of training centers perform on average 1-100 laparoscopic procedures per year. 
Only $25 \%$ of the respondents have access to laparoscopic trainers at their department or have their own training box. Self-study as a method of training, more than once a week, was mentioned by $32 \%$ and $60 \%$ of UR with and without access to laparoscopic training, respectively (Figure 1).

The most popular form of additional education, apart from compulsory residency, is national laparoscopic courses (Figure 2). Only a small percentage of UR participated in national and international internships and courses.

Most of the individuals undergoing training (61\%) are aware of the possibility to receive a certificate of laparoscopic skills during the E-BLUS examination (European-Basic Laparoscopic Urological Skills); $73 \%$ of these individuals are considering taking the examination (Figure 3).

Figure 4 presents the UR level of advancement in performing laparoscopic procedures in each year of

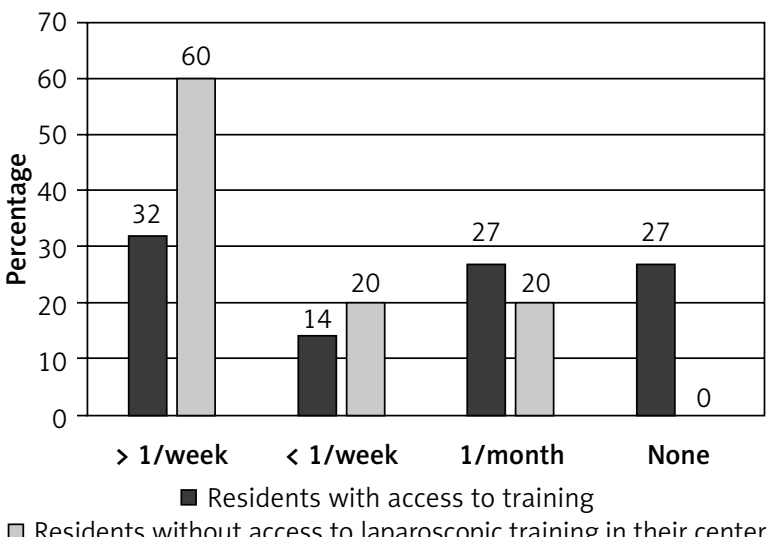

Figure 1. Percentage of UR who reported training on a laparoscopic box

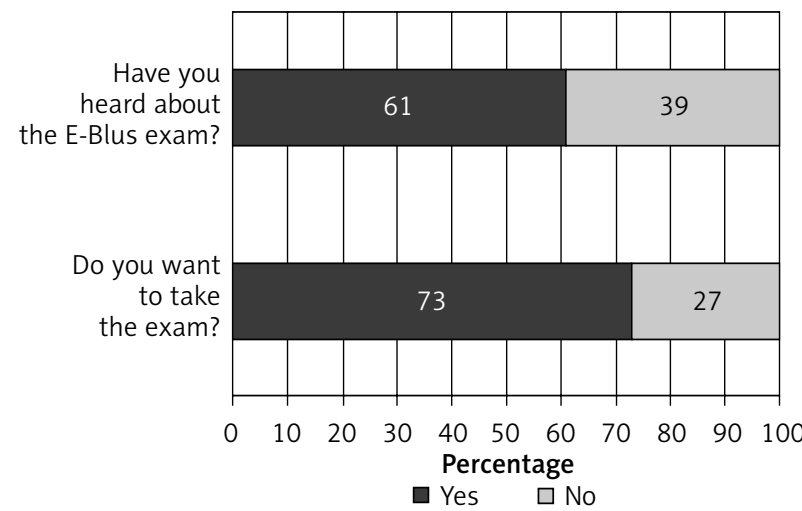

Figure 3. Level of knowledge and willingness to take the E-BLUS examination (all UR) their residency. From the very first year of training, all participants of the study report their participation in laparoscopic procedures as second assistants (laparoscopic camera operator). As the specialty training progresses, the number of UR assisting with surgical procedures as first assistants and operating surgeons increases. All UR of the last year of training state that they perform laparoscopic procedures as operating surgeons. In view of the disproportionate distribution of survey participants in individual years of training, significance statistical analysis was not performed.

The most common laparoscopic procedures performed by the study participants included varicocele ligation (71\% of respondents) and marsupialization of renal cysts (41\%). Advanced laparoscopic procedures are performed by a small percentage of UR (Table II).

Among the UR who had access to laparoscopic training in their centers, only $28 \%$ considered their

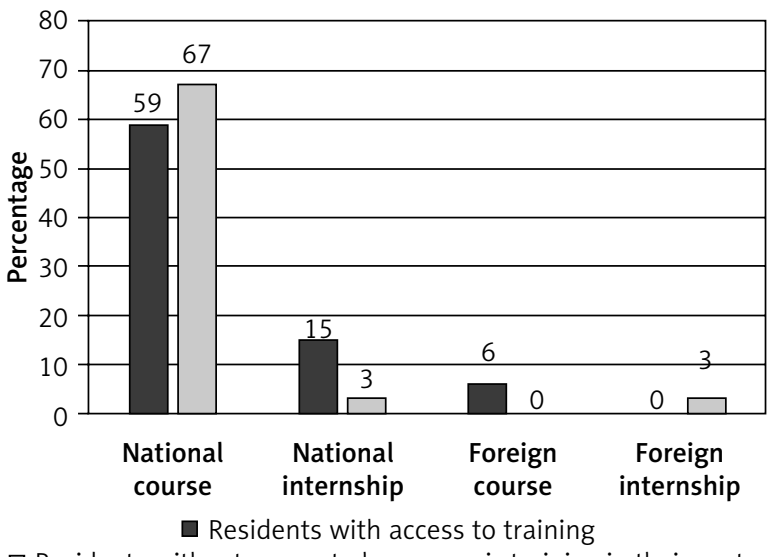

$\square$ Residents without access to laparoscopic training in their center

Figure 2. Forms of education of UR

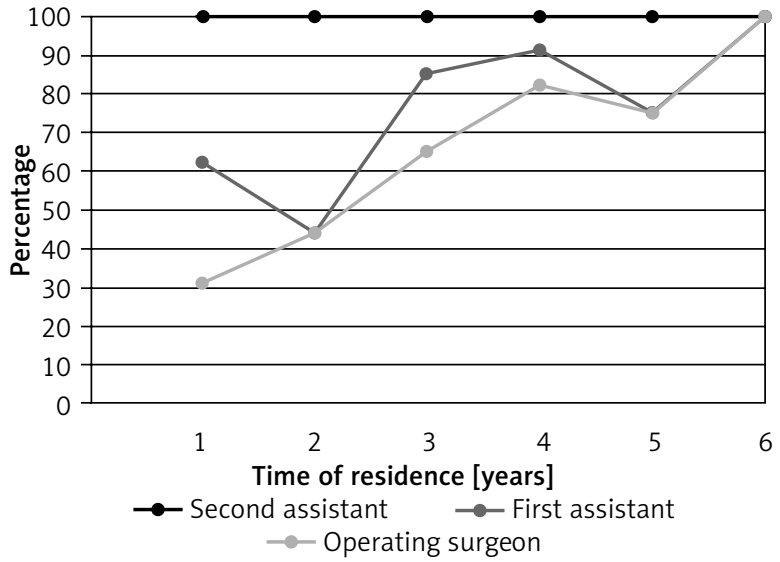

Figure 4. UR participation in laparoscopic procedures in each year of residency 
current laparoscopic skills as at least satisfactory. However, no participant from the group of participants without access to laparoscopic training considered their skills as positive (Figures 5, 6).

In response to the question about the expected level of laparoscopic skills at the end of specialty training, we observed a significant shift towards "satisfactory" (37\%), "good" (14\%), and "very good" (10\%) among UR with access to laparoscopic training. In the second group, the most frequent answer to the above question was "very weak" (50\%). Moreover, analyzing the same issue from the perspective of senior UR ( $>4^{\text {th }}$ year) and junior UR $\left(<4^{\text {th }}\right.$ year $)$, the former reported having more experienced at the

Table II. Number of procedures performed by UR with access to laparoscopic surgery in their department

\begin{tabular}{|c|c|c|}
\hline Procedure & $\begin{array}{l}\text { Number of } \\
\text { procedures }\end{array}$ & $\%$ \\
\hline \multirow[t]{3}{*}{ Varicocele ligation } & 0 & 29 \\
\hline & $1-5$ & 40 \\
\hline & $>5$ & 31 \\
\hline \multirow[t]{3}{*}{ Renal cyst marsupialization } & 0 & 59 \\
\hline & $1-5$ & 32 \\
\hline & $>5$ & 9 \\
\hline \multirow[t]{3}{*}{ Ureterolithotomy } & 0 & 82 \\
\hline & $1-5$ & 17 \\
\hline & $>5$ & 1 \\
\hline \multirow[t]{3}{*}{ Radical nephrectomy } & 0 & 79 \\
\hline & $1-5$ & 14 \\
\hline & $>5$ & 7 \\
\hline \multirow[t]{3}{*}{ Pyeloplasty } & 0 & 88 \\
\hline & $1-5$ & 9 \\
\hline & $>5$ & 3 \\
\hline \multirow[t]{3}{*}{ Radical prostatectomy } & 0 & 86 \\
\hline & $1-5$ & 9 \\
\hline & $>5$ & 5 \\
\hline \multirow[t]{3}{*}{ NSS } & 0 & 88 \\
\hline & $1-5$ & 10 \\
\hline & $>5$ & 2 \\
\hline
\end{tabular}

time of survey and also in their expected experience at the end of residency, but this difference was not significant ( $p=0.3938, p=0.4773$ ) (Figures 7,8$)$.

\section{Discussion}

The traditional model of education practiced in open surgery is based on the "master-apprentice" relationship - see one, do one, teach one. The laparoscopic technique has its limitations associated with the loss of three-dimensional vision and depth perception, compared to open surgery, and, above all, a long learning curve. Acquisition of knowledge and practical skills in the traditional model in the case of laparoscopic and robot-assisted techniques

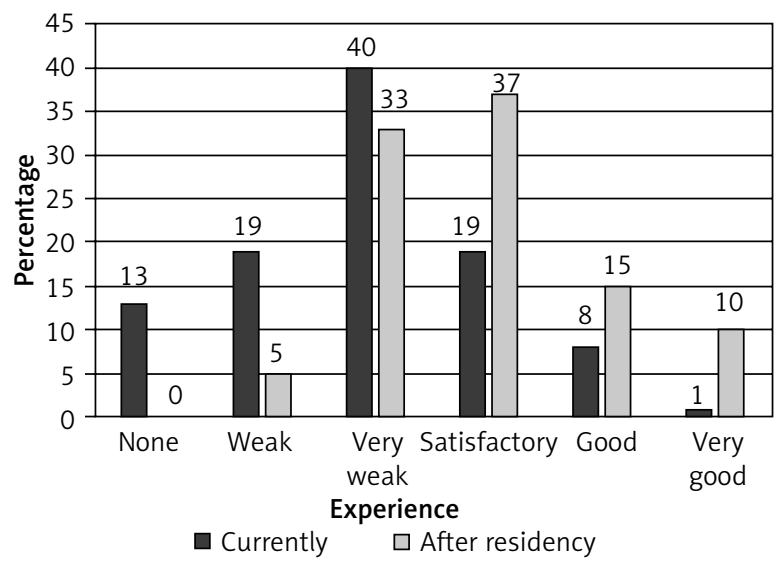

Figure 5. Laparoscopic experience of UR with access to laparoscopic surgery in their departments

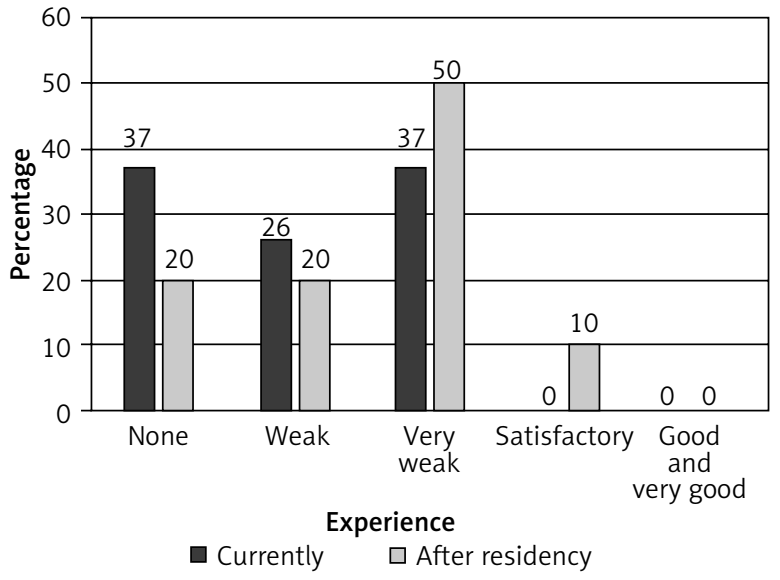

Figure 6. Laparoscopic experience of UR without access to laparoscopic surgery in their departments 


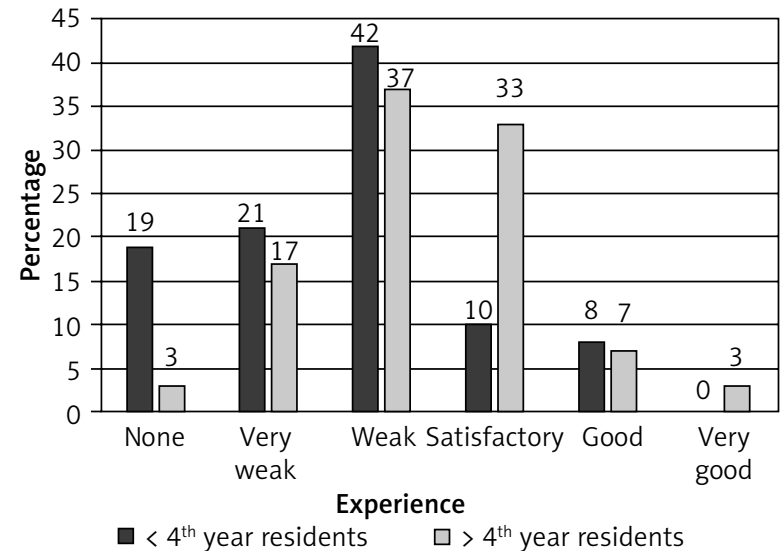

Figure 7. Laparoscopic experience of junior and senior UR at the time of the survey (all UR)

is not effective [10]. Furthermore, with a growing debate about whether it is safe and/or ethical to train on patients there is a clear need for change of traditional surgical education. A well-designed laparoscopic training program is one of the key conditions for implementation of minimally invasive methods in everyday medical practice. Based on the conducted research and experiments, laparoscopic and robotic curricula were created which precisely describe the educational path of training conducted under the auspices of European and national associations and sections $[11,12]$.

There is no doubt that basic laparoscopic skills should first be taught outside the operating theatre, emphasizing the role of exercises on laparoscopic training equipment (box trainers, pelvic trainer) [13]. This form of training provides the opportunity to use up-to-date tools and acquire basic laparoscopic skills, such as manipulation, preparation, suturing, binding, cooperation of both hands, and visual and motor coordination. The obtained data indicate that the majority of the respondents do not apply the method of self-improvement. Only about 25\% of all urology departments possess laparoscopic training equipment, and $32 \%$ of UR from the group with such training possibilities practice regularly at least once a week. These numbers differ significantly from the values of European centers, where over $60 \%$ of treatment units have their own manual skills improvement laboratory and the reported period of time spent practicing is more than 90 min a day [8]. The gold standard of training should be training using a box trainer for at least one hour a day following a clearly defined schedule [14].

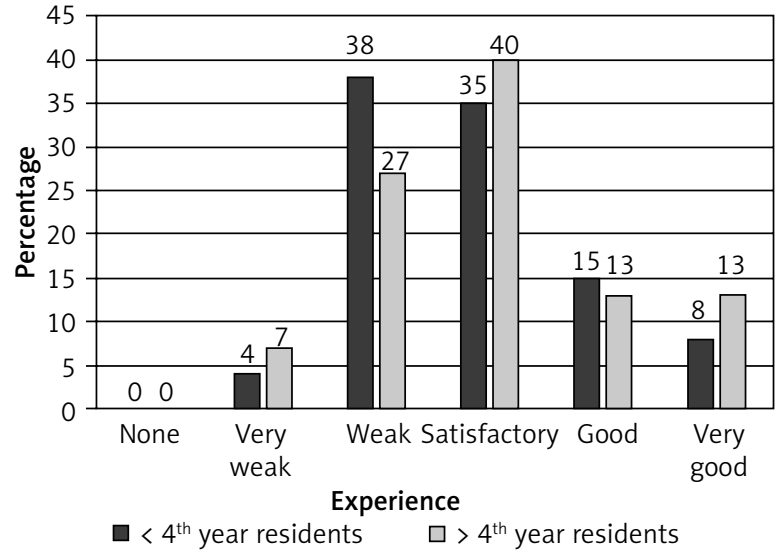

Figure 8. Expected laparoscopic experience of junior and senior UR at the end of residency (all UR)

The preferred method of validation learning of basic laparoscopic skills seems to be the certified E-BLUS (European-Basic Laparoscopic Urological Skills) examination conducted by the EAU Section of Uro-Technology (ESUT). The examination consists of a theoretical part and a strictly standardized practical part, which includes performance of individual exercises with qualitative assessment within specified time criteria [15]. The E-BLUS examination is conducted annually during the EUREP and EAU Congress. The analysis of the first edition of the E-BLUS examination during EUREP in 2015 revealed that most of participants did not pass the examination. The most common cause of failure among trainees is not meeting the time criteria set for the exercises [16]. The authors of the publication emphasize that the reason for failure is insufficient time spent on exercises with the box trainer before taking the examination. It seems that regular popularization and organization of the E-BLUS examination in Poland by leading centers coordinating laparoscopic education may encourage trainees to become more involved in laparoscopic training and might promote this technique. So far this examination has been conducted in Poland twice - in 2015 and 2017 - by the Urology Department of the Jan Biziel University Hospital in Bydgoszcz.

Training of basic laparoscopic skills on box trainers has a limited impact on the overall operative performance of trainees during in vivo laparoscopic surgery. Training of advanced laparoscopic skills with simulation is another significant step of education described in most laparoscopic curricula. In urology there are various simulation models avail- 
able, including revitalized animal tissues, synthetic materials, anesthetized animals, and virtual simulators [17]. The advantage of using a simulator is the possibility of learning individual procedures in practice outside the operating theatre, in comfortable conditions, with multiple attempts available. Many new virtual simulation devices have recently emerged on the medical market and allow learning such advanced urological procedures as radical prostatectomy or radical nephrectomy. Virtual simulators enable quantitative evaluation of the economics and purposefulness of movements, time, and the number of mistakes made. It is expected that in the future surgical simulators will also enable one to demonstrate crisis situations - intraoperative complications, adverse events and anatomical anomalies [18]. Currently in Poland there are few training centers using virtual simulators, and commercial courses with animal preparations or anesthetized animals are available to improve skills in selected urological procedures, such as radical prostatectomy or radical nephrectomy.

Extending knowledge and laparoscopic skills during courses and internships is a recognized stage in education [19]. Our study showed that only $15 \%$ of the trainees had the opportunity to participate in national internships and nearly $60 \%$ of respondents attended additional national courses, while a much lower percentage took the courses abroad. It should be stressed that this form of education is also chosen by residents who do not have the opportunity to practice laparoscopy at their home centers, which emphasizes their strong motivation to gain knowledge and skills. In response to the open question regarding the level of satisfaction with the system of courses and internships, the most frequently given answer concerned the limited number, the need for individual financing, and the difference in the quality. The key aspect is, therefore, the better quality of the courses and internships and their impact on further surgical practice. Similar issues are also emphasized by UR in surveys from other countries.

The importance of learning non-technical skills is gradually gaining recognition in the education of surgeons. Non-technical skills are defined as abilities to communicate, work in a team and respond to stress while performing surgical procedures [20]. It appears that an appropriate scope of training, including the ability to select and assess information, work in a team, and make decisions, is as import- ant as learning of manual skills and directly translates into treatment outcomes [21]. A poor level of non-technical skills can lead to surgical error, and it is proven that non-technical skills do not correlate with surgical experience. It is, therefore, justified to create laparoscopic teams consisting of well-cooperating urologists, anesthesiologists, and scrub nurses trained for laparoscopy. The number of laparoscopic operating surgeons per resident, which in Poland is currently around 1 to 11 , may contribute to the development of non-technical skills among UR. Non-technical skills should also be incorporated in training programs of UR and can be improved during special courses with simulation.

Once the basic laparoscopic and theoretical skills have been mastered, the surgeons undergoing training can begin their education in the operating theatre, where they should learn skills in an appropriate order and conduct increasingly difficult procedures, with the learning curve being individually adjusted. Procedures conducted with the participation of a surgeon in training should be organized with the minimal risk for patients. Increased rates of pre- and postoperative complications or worse treatment outcomes should not be regarded as an acceptable cost of learning opportunities. Therefore, treatment of the patient is a priority, and the educational aspect must still be secondary, especially during live operations [22]. According to our survey, over $70 \%$ of urology centers in Poland provide training in laparoscopic technique. This level is comparable to the average for Western European countries, but differs from such countries as the USA and Canada, where it is close to $100 \%$ [8]. Almost all trainees, starting from the $1^{\text {st }}$ year of training, participated in laparoscopic procedures not only as assistants, but also as surgeons. Similarly to other European countries, the most common procedures performed by UR are varicocele ligation and renal cyst marsupialization. Out of the group of Polish UR $41 \%$ reported having performed at least one laparoscopic marsupialization of renal cysts compared to $21 \%$ of UR in other European countries [7]. A much smaller percentage of UR performed advanced procedures such as nephrectomy, radical prostatectomy, or NSS ( $>1$ LRP procedure $-14 \%$ Poland vs. $12 \%$ Europe), which was caused mainly by the long learning curve of these procedures. It should be noted that the number of procedures carried out by doctors in Poland during their specialty training is comparable to the average 
in Western Europe, where, as in Poland, most UR develop their manual skills as $1^{\text {st }}$ and $2^{\text {nd }}$ assistants, with only a small group practicing as operating surgeons $[3,7,8]$. In contrast, most describe their skills in this field as weak or very weak, and only $19 \%$ consider them satisfactory, but a significant proportion of the respondents are motivated to continue education and approximately $60 \%$ state that their level of experience at the end of the training will be at least satisfactory. The UR from other countries, where access to these techniques is more common, consider their skills to be at a similar level.

Effective teaching of UR complex procedures such as radical prostatectomy or radical nephrectomy is challenging and demands superior conditions such as mentoring. Modular training is one of the proposed forms of structured mentoring [23]. The idea behind modular training is to teach procedures under the supervision of an experienced surgeon by dividing them into stages of varying difficulty. In modular training the trainee first assists a procedure as a laparoscopic camera operator, learning the different stages of the procedure and the dexterity in using tools. Upon mastering this step, the surgeon starts training as the first assistant to improve his or her skills. The next step is to perform individual stages of the procedure, starting with the simplest ones. The mentor assesses progress of the trainee and, upon mastering a given stage of the procedure, allows him or her to move on to the next - more complex stage, until the trainee finally masters the entire procedure. Modular training is used in urology to teach mainly radical prostatectomy and radical nephrectomy $[24,25]$. Study authors stress the importance of the learning curve, which for radical prostatectomy is within the range of 200-250 procedures [26]. An obvious condition for beginning practical education in the operating theatre, according to the studies quoted above, is mastering the theoretical background as well as technical and non-technical skills in the previous stages of training. Internships in "high-volume centers", where trainees have an opportunity to refine individual aspects of their technique under the supervision of the most experienced surgeons, also play a dominant role at this stage of education [27].

\section{Conclusions}

Minimally invasive surgical techniques are now taught according to a strictly defined formula, which consists of a few key points, such as exercises using a training box, simulations, courses/internships, and transition to clinical practice in a clearly specified order. Non-technical skills have also been recently included in the training process and are now taught during specially designed courses. At each stage of the training the surgeon's competence is objectively assessed and certified. This model is based on the principles of evidence-based medicine and parameterized evaluation of training results, constituting the gold standard in English-speaking and Western countries (Figure 9).

Our research shows that the laparoscopic education program for UR in Poland has similar limitations to those present in other European countries. It is necessary to continue cooperation in order to promote minimally invasive techniques, equipping urology units with laparoscopic training equipment, creating simulation centers, as well as increasing the availability of internships, courses and establishing a data management system. It should be noted that the study group was relatively small and did not encompass all UR. It also did not include information on the willingness of the participants to develop their own careers in laparoscopic techniques.

It seems optimal to further evaluate and regularly assess the quality of the training offered at regular

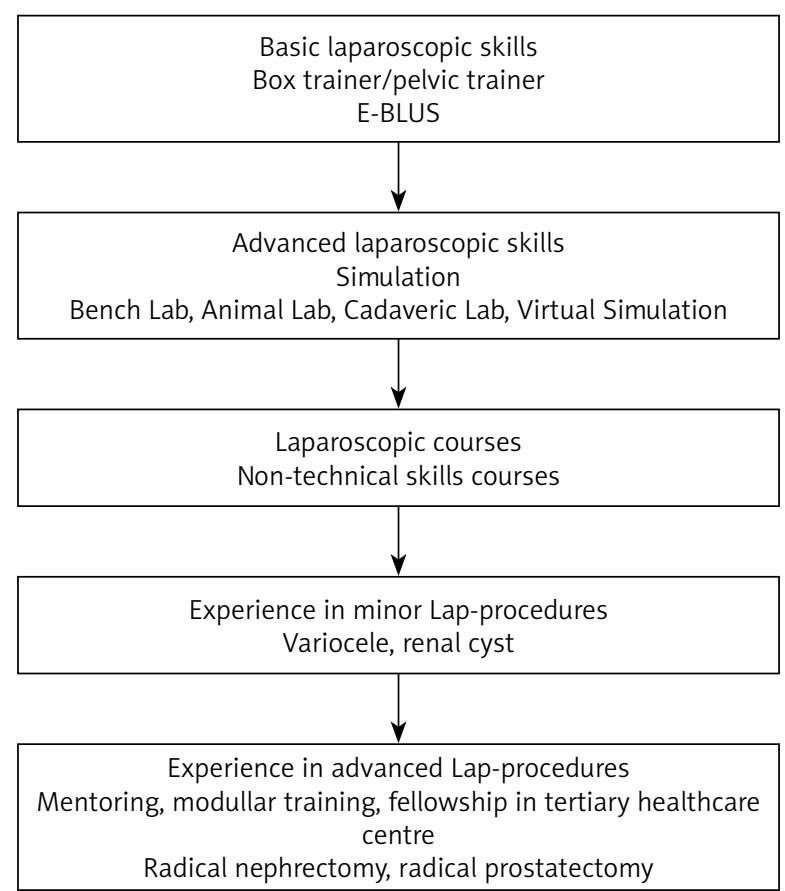

Figure 9. Proposed training pathway in laparoscopic education 
intervals in order to accurately verify the direction of changes in laparoscopic training for young urologists in Poland.

\section{Conflict of interest}

The authors declare no conflict of interest.

\section{References}

1. Lowrance WT, Eastham JA, Savage C, et al. Contemporary open and robotic radical prostatectomy practice patterns among urologists in the United States. J Urol 2012; 187: 2087-92.

2. Dobruch J, Chłosta P, Szopiński T, et al. Laparoskopia w urologii. Postep Nauk Med 2012; 4: 351-5.

3. Furriel FT, Laguna MP, Figueiredo AJ, et al. Training of European urology residents in laparoscopy: results of a pan-European survey. BJU Int 2013; 112: 1223-8.

4. Kumar U, Gill IS. Learning curve in human laparoscopic surgery. Curr Urol Rep 2006; 7: 120-4.

5. Abboudi H, Khan MS, Guru KA, et al. Learning curves for urolog ical procedures: a systematic review. BJU Int 2014; 114: 617-29.

6. Borówka A, Dobruch J, Antoniewicz A, et al. Nauczanie laparoskopii w urologii. Prz Urol 2007; 41: 17-22.

7. De Win G, Everaerts W, De Ridder D, Peeraer G. Laparoscopy training in Belgium: results from a nationwide survey, in urology, gynecology, and general surgery residents. Adv Med Educ Pract 2015; 6: 55-63.

8. Qureshi A, Vergis A, Jimenez C, et al. MIS training in Canada: a national survey of general surgery residents. Surg Endosc 2011; 25: 3057-65.

9. Duchene DA, Moinzadeh A, Gill IS, et al. Survey of residency training training in laparoscopic and robotic surgery. J Uro 2006; 176: 2158-66.

10. Brinkman WM, Havermans SY, Buzink SN, et al. Single versus multimodality training basic laparoscopic skills. Surg Endosc 2012; 26: 2172-8.

11. van der Poel $\mathrm{H}$, Brinkman W, van Cleynenbreugel B, et al. Training in minimally invasive surgery in urology: European Association of Urology/International Consultation of Urological Diseases consultation. BJU Int 2016; 117: 515-30.

12. Mottrie A, Novara G, van der Poel H, et al. The European Asso ciation of Urology Robotic Training Curriculum: an update. Eur Urol Focus 2016; 2: 105-8.

13. Buzink S, Soltes M, Radonak J, et al. The Laparoscopic Surgical Skills programme: setting the European standard. Videosurgery Miniinv 2012; 7: 188-92.

14. Kiely DJ, Stephanson K, Ross S. Assessing image quality of lowcost laparoscopic box trainers: options for residents training at home. Simul Healthc 2011; 6: 292-8.

15. http://uroweb.org/education/live-events/hands-on-trainingcourses/laparoscopy/european-training-in-basic-laparoscopic-urological-skills-e-blus.

16. Brinkman WM, Tjiam IM, Schout BM, et al. Results of the European basic laparoscopic urological skills examination. Eur Urol 2014; 65: 490-6.
17. Ahmed K, Jawad M, Abboudi M, et al. Effectiveness of procedural simulation in urology: a systematic review. J Urol 2011; 186: 26-34.

18. Ryan P. The current role of simulation in urological training. Cent Eur J Urol 2015; 68: 207-11.

19. Hay D, Khan MS, Van Poppel H, et al. Current status and effectiveness of mentorship programmes in urology - a systematic review. BJU Int 2015; 116: 487-94.

20. Brunckhorst O, Khan MS, Dasgupta P, Ahmed K. Nontechnical skill training and the use of scenarios in modern surgical education. Curr Opin Urol 2017; 27: 330-6.

21. Brunckhorst O, Volpe A, van der Poel H, et al. Training, simulation, the learning curve, and how to reduce complications in urology. Eur Urol Focus 2016; 2: 10-8.

22. Cumpanas A, Ferician O, Latcu S, et al. Ethical, legal and clinical aspects of live surgery in urology - contemporary issues and a glimpse of the future. Videosurgery Miniinv 2017; 12: 1-6.

23. Lund L, Dubrowski A, Carnahan H. A modular approach for training urologists in laparoscopy. BJU Int 2007; 100: 1216-8.

24. Stolzenburg JU, Schwaibold H, Bhanot SM, et al. Modular surgical training for endoscopic extraperitoneal radical prostatectomy. BJU Int 2005; 96: 1022-7.

25. Stewart GD, Phipps S, Little B et al. Description and validation of a modular training system for laparoscopic nephrectomy. J Endourol 2012; 26: 1512-7.

26. Abboudi H, Khan MS, Guru KA, et al. Learning curves for urological procedures: a systematic review. BJU Int 2014; 114: 617-29.

27. Al-Kandari AM, Elshebiny $\mathrm{Y}$, Ibrahim $\mathrm{H}$, et al. Can endourology fellowship training enhance minimally invasive surgery in urology practice? Arab J Urol 2016; 14: 275-9.

Received: 15.10.2018, accepted: 5.12.2018. 


\section{Appendix 1.}

\section{Questionnaire}

1. What is your year of residency?

2. What type is your hospital? Academic center $\square$ Other $\square$

3. Do you have access to laparoscopic training in your center? Yes $\square \quad$ No

4. How many laparoscopic surgeons does your department have?

5. How many urology residents does your department have?

6. How many urologic laparoscopic procedures are performed in your department each year?
0
$<50$
$>50<100$
$>100<150$
$>200$

7. Do you have access to laparoscopic training facilities in your center? Yes

8. What kind of participation in laparoscopy does your department offer to residents?
a) Camera operator
b) First assistant
c) Operating surgeon
d) Laparoscopic box training
e) Virtual training

9. How many laparoscopic procedures have you performed as first surgeon (consider procedures in which you performed at least half of the surgical steps)?

\begin{tabular}{|l|c|c|c|}
\hline Procedure & 0 & $1-5$ & $>5$ \\
\hline Varicocele ligation & & & \\
\hline Renal cyst marsupialization & & & \\
\hline Ureterolithotomy & & & \\
\hline Radical nephrectomy & & & \\
\hline Pyeloplasty & & & \\
\hline Radical prostatectomy & & & \\
\hline Nephron-sparing surgery & & & \\
\hline
\end{tabular}

10. Do you have your own laparoscopic training box? Yes

No

11. How often do you train with the laparoscopic box?

More than once per week $\square \quad$ Less than once per week

Once per month $\square \quad$ I do not train at all $\square$

12. Have you ever taken part in any laparoscopy course or fellowship?

Yes, national course $\square$ Yes, foreign course

Yes, national fellowship Yes, foreign fellowship

No, I have not

13. Have you heard about the E-Blus exam?

14. Do you want to take the E-Blus exam?

Yes

Yes

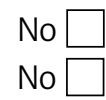

15. How do you rate your current laparoscopic experience?
None $\square$
Very weak
Weak $\square$
Satisfactory $\square \quad$ Good
Very good $\square$

16. What is your expected laparoscopic experience at the end of residency?

None $\square \quad$ Very weak $\square \quad$ Weak $\square \quad$ Satisfactory $\square \quad$ Good $\square \quad$ Very good $\square$

17. Are you satisfied with the system of laparoscopic education in urology?

Yes $\square$

No

If no, please write the reason 